\title{
CUSUM charts in the quality control of colon cancer lymph node analysis: a population-registry study
}

\author{
Carlos Fortea-Sanchis $^{{ }^{*}} \mathbb{D}$, David Martínez-Ramos ${ }^{2}$ and Javier Escrig-Sos ${ }^{2}$
}

\begin{abstract}
Background: The most important determinant of survival in patients with colon cancer is the presence or absence of regional lymph node metastases. This factor is consistently associated with long-term and disease-specific survival. Cumulative summation of differences (CUSUM) charts can help to discriminate abnormalities that cannot be explained by the general variability of a process. We used CUSUM charts to analyse the quality of nodal analysis in colon cancer and to use a population-registry cancer database to estimate the optimal number of lymph nodes for adequate prognostic analysis.
\end{abstract}

Methods: This was a multicentre population-registry cancer study from January 2004 to December 2007. We used these data to produce the different CUSUM curves, focusing on the main variables. To calculate survival, we used the Kaplan-Meier method.

Results: In this study, we examined 548 patients. The CUSUM curves were calculated for overall mortality, specific mortality, and recurrence according to (1) the number of lymph nodes analysed and affected and (2) compared the ratio of the number of lymph nodes affected to the number analysed. Finally, the lymph node ratio was compared to the overall survival CUSUM curve.

Discussion: This CUSUM control chart analysis reinforces the unquestionable importance of analysing at least 12 lymph nodes in patients with colon cancer in order to accurately estimate their prognosis. However, our findings indicate that the analysis of at least 20 lymph nodes is a more appropriate cutoff point for accomplishing the demanding objective of diagnosing a high-quality prognosis in colon cancer patients.

Keywords: Colon cancer, Lymph nodes, Survival, Quality control

\section{Background}

Colorectal cancer is the third most common cancer worldwide and is the most frequent malignancy in many Western countries. Approximately 2359 new cases are diagnosed per 100,000 individuals each year, and it is the second leading cause of death from cancer both in men and women in Spain (after lung and breast cancer, respectively) [1]. After distant metastases, the second most important determinant of survival among patients with colon cancer is the presence or absence of regional lymph

\footnotetext{
* Correspondence: carlosfortea@gmail.com

${ }^{1}$ Department of Surgery, Division of Colorectal Surgery, Consorcio Hospitalario Provincial de Castellón, Av. Doctor Clara, 19, 12002 Castellón, Spain

Full list of author information is available at the end of the article
}

node metastases. This factor is consistently associated with long-term and disease-specific survival [2, $3]$, and the presence of these metastases has important implications because it may determine the use of adjuvant therapies [2, 4]. Furthermore, the total number of lymph nodes evaluated (even those negative for metastasis) is consistently associated with disease-specific survival in patients with stage II and III cancer as well as with long-term disease survival $[2,3,5]$.

The recommended number of lymph nodes for analysis in colon cancer ranges from 6 to more than 30 nodes and has been repeatedly scrutinised in the

(c) The Author(s). 2018 Open Access This article is distributed under the terms of the Creative Commons Attribution 4.0 International License (http://creativecommons.org/licenses/by/4.0/), which permits unrestricted use, distribution, and reproduction in any medium, provided you give appropriate credit to the original author(s) and the source, provide a link to the Creative Commons license, and indicate if changes were made. The Creative Commons Public Domain Dedication waiver (http://creativecommons.org/publicdomain/zero/1.0/) applies to the data made available in this article, unless otherwise stated. 
literature using different statistical methods in an attempt to identify an optimal cutoff number $[6,7]$. Generally, 12 is considered the gold standard for colon cancer, although no studies have specifically demonstrated that this number is the most advantageous. Moreover, using classical statistical methods, it is difficult to discriminate specific differences presented by any given procedure from their general variability or any of their other variables.

Cumulative summation of differences (CUSUM) charts are used in quality control for industrial processes because they can help to discriminate abnormalities that cannot be explained by the general variability of a process. In clinical care processes, this property can be applied to identify which sections of an outcome influence a variable that can affect the result. Therefore, CUSUM charts are also useful for assessing the learning curve and for more generally assessing quality-of-care results [8-11]. However, this analysis system has not yet been tested for lymph node analyses in colorectal cancer. Thus, here, we used CUSUM charts to analyse the quality of nodal analysis in colon cancer and to use a population-registry cancer database to estimate the optimal number of lymph nodes for adequate prognostic analysis.

\section{Methods}

This was a multicentre population-registry cancer study; data from this registry are included in the EUROCARE study [12]. The study period was from January 2004 to December 2007, and the inclusion and exclusion criteria are shown in Table 1. The variables used were age, gender, location, size, histology, grade of differentiation and tumour extension, number of lymph nodes analysed, number of lymph nodes affected, lymph node ratio (LNR)-i.e. the ratio of affected lymph nodes to those analysed, year of diagnosis, specific and overall survival, date

Table 1 Inclusion and exclusion criteria

\begin{tabular}{ll}
\hline Inclusion criteria & Exclusion criteria \\
\hline $\begin{array}{l}\text { Surgery with curative intent with } \\
\text { lymph node resection }\end{array}$ & $\begin{array}{l}\text { Palliative surgery without } \\
\text { lymphadenectomy }\end{array}$ \\
Full pathology report & Incomplete pathology report \\
Clear clinical status at last & Doubtful clinical status at the last \\
follow-up & follow-up \\
Colon tumours & Appendiceal and rectal tumours \\
& Surgery without resection \\
& Metastasis at diagnosis \\
& Inadequate follow-up \\
\hline
\end{tabular}

of metastasis or recurrence, follow-up time, and TNM stage and condensed TNM-both according to the sixth edition of the Union for International Cancer Control (UICC).

CUSUM graphs were used to distinguish different groups within continuous-type prognostic variables following the method described by Barrio et al. [13]. To identify the cutoff, we calculated the predicted probabilities using logistic regression for a binary variable resulting from a continuous prognostic variable. The thresholds are determined by the CUSUM graphs we used to monitor the trend changes in the probabilities calculated by this type of logistic regression, as well as these changes in trend themselves [14].

We used these data to produce the different CUSUM curves, focusing on the main variables. First, we calculated a CUSUM curve for overall mortality according to the number of lymph nodes analysed and affected. Second, we compared specific mortality with the number of lymph nodes analysed and affected. Finally, we used the CUSUM chart to calculate predicted overall survival according to the LNR. To calculate survival, we used the KaplanMeier method. All our analyses and the generation of the CUSUM graphs were carried out using SPSS, version 17.0, for Windows.

\section{Results}

During this 4-year study, 944 patients were diagnosed with colon cancer; 279 did not fulfil the inclusion criteria and a further 116 cases with metastases at diagnosis were also excluded. Thus, a total of 548 patients were examined in this study; their main epidemiological and tumour characteristics are summarised in Table 2. A total of 6400 lymph nodes were analysed (median 10 nodes per case; range 145). Fewer than 12 lymph nodes were analysed in 310 patients $(56.3 \%)$ while 12 or more lymph nodes were checked in 241 cases (43.7\%). The median follow-up time was 51 months (range 0-99 months). During follow-up, metastases appeared in 92 cases (16.7\%), there was a local recurrence in 39 cases (7.1\%), and 214 patients died (38.8\%). According to our Kaplan-Meier analysis, the 5- and 10-year overall survival was $89 \%$ and $79 \%$, respectively. The 5 -year disease-specific survival rates were $95 \%$ and $88 \%$ at 10 years, and the 5-year disease-free survival (without metastases or recurrences) was $90 \%$ and $81 \%$ at 10 years.

The CUSUM curve for overall mortality was calculated according to the number of lymph nodes analysed (Fig. 1a). This graph shows that the risk of 
Table 2 Epidemiological and tumour characteristics

\begin{tabular}{ll}
\hline & $n=548$ \\
\hline Age $^{*}$ & $72(63-80)$ \\
Grouped age & $109(19.9 \%)$ \\
$<60$ & $222(40.5 \%)$ \\
$>75$ & $217(39.6 \%)$ \\
Gender & \\
Female & $252(46 \%)$ \\
Male & $296(54 \%)$ \\
Tumour location & \\
Right colon & $195(35.6 \%)$ \\
Transverse colon & $58(10.6 \%)$ \\
Left colon & $44(8.0 \%)$ \\
Sigmoid colon & $217(39.6 \%)$ \\
Unknown & $34(6.2 \%)$ \\
Histology & \\
Adenocarcinoma & \\
Mucinous & $461(84.7 \%)$ \\
Signet-ring cell & $74(13.6 \%)$ \\
Major size (mm)* & $9(1.7 \%)$ \\
Grade & $45(32-55)$ \\
Unknown & $343(62.6 \%)$ \\
I & $35(6.4 \%)$ \\
III & $19(3.5 \%)$ \\
\hline
\end{tabular}

Adjuvant chemotherapy

No

Yes

Number of retrieved lymph nodes*

Cutoff retrieved lymph nodes

$<12$

$\geq 12$

Number of positive lymph nodes*

Lymph node ratio

$0-24$

$25-60$

$>60$

Condensed pT6

$$
\mathrm{T} 1-\mathrm{T} 2
$$$$
\text { T3-T4 }
$$

Condensed pN7

No

N1

N2

Condensed TNM stage
Table 2 Epidemiological and tumour characteristics (Continued)

\begin{tabular}{ll}
\hline & $n=548$ \\
\hline$\|$ & $253(46.2 \%)$ \\
Postoperative death (90 days) & $202(36.8 \%)$ \\
No & $503(91.8 \%)$ \\
Yes & $45(8.2 \%)$ \\
Follow-up general mortality & \\
No & $334(60.9 \%)$ \\
Yes & $214(39.1 \%)$ \\
Follow-up recurrence & \\
No & $439(80.1 \%)$ \\
Yes & $109(19.9 \%)$ \\
Follow-up time (months)* & $51(30-64)$ \\
\hline *Median (IOR: interquartile range) &
\end{tabular}

mortality initially tended to increase (downward trend) until approximately 12 nodes were analysed; after this, there was a trend of falling risk (upward curve) until approximately 20 nodes were analysed; at this point, the risk slowly increased (the curve rises slowly). These trend changes translate into a significant increase in the probability of death when fewer than 12 lymph nodes were analysed. From a practical standpoint, these results indicate that analysing fewer than 12 lymph nodes favours worse outcomes; the intensity of this correlation subsequently decreases (but is not null) and stabilises at around 20 nodes (Fig. 1a). Consequently, producing an accurate prognostic diagnosis in patients with colon cancer requires the retrieval of at least 20 lymph nodes (and never fewer than 12).

Figure 1b compares the general mortality to the number of lymph nodes affected and shows that the risk of mortality tends to increase in line with the number of affected lymph nodes (between 1 to 10 affected lymph nodes), as seen as in the area where the curve descends; after this point, the trend stabilises. As predicted, the risk of mortality increases as a function of the number of lymph nodes affected. A comparison of specific mortality versus the number of lymph nodes analysed initially shows high fluctuation above and below the null line, but a strong trend of decreasing specific mortality clearly emerges after 21 lymph nodes are analysed (Fig. 2a). The CUSUM graph analysis of the specific mortality according to the number of affected nodes (Fig. 2b) showed a marked increase in the mortality risk trend when between 1 and about 10 affected lymph nodes were found (downward curve), followed by a slower trend of increasing mortality risk. This 

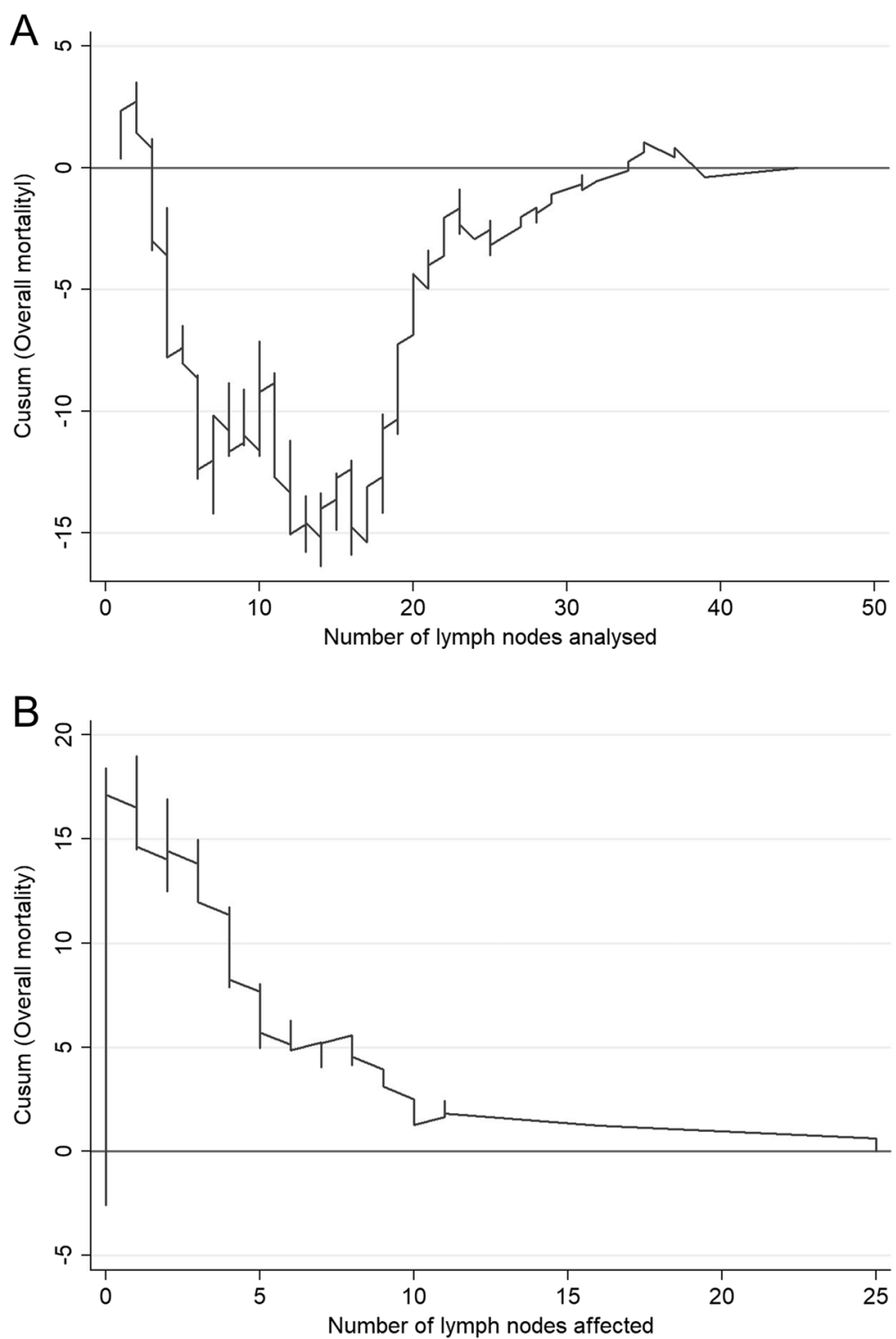

Fig. 1 CUSUM curves. a Overall mortality according to the number of lymph nodes analysed. b Overall mortality according to the number of lymph nodes affected

means that the differential mortality risk increased linearly as more positive nodes were analysed. As in its counterpart graph for mortality (Fig. 2a), there is a clear relationship between the number of affected lymph nodes and recurrence (Fig. 3a), even when many lymph nodes were analysed (Fig. 3b).

The CUSUM curve comparing the ratio of the number of lymph nodes affected by the number analysed (Fig. 4) highlights two clear trends: the odds of finding affected lymph nodes decreases until 10-11 lymph nodes are analysed, after which the probability increases to stabilise at 23-24 nodes, and there is no clear increase in the probability of finding more positive nodes. Finally, according to the LNR versus overall survival CUSUM curve, the risk of death clearly and consistently increases when the LNR was $20 \%$ or more (Fig. 5). When LNR was compared with the $\mathrm{pN}$ category (Fig. 6), the pN1 and pN2 categorisation perfectly matched the $20 \%$ LNR when high-quality nodal analysis (i.e. on more than 20 lymph nodes) was carried out.

\section{Discussion}

Given the importance of lymph node analysis in colon cancer, many studies have been conducted in this field [2-5]; however, this is the first time 

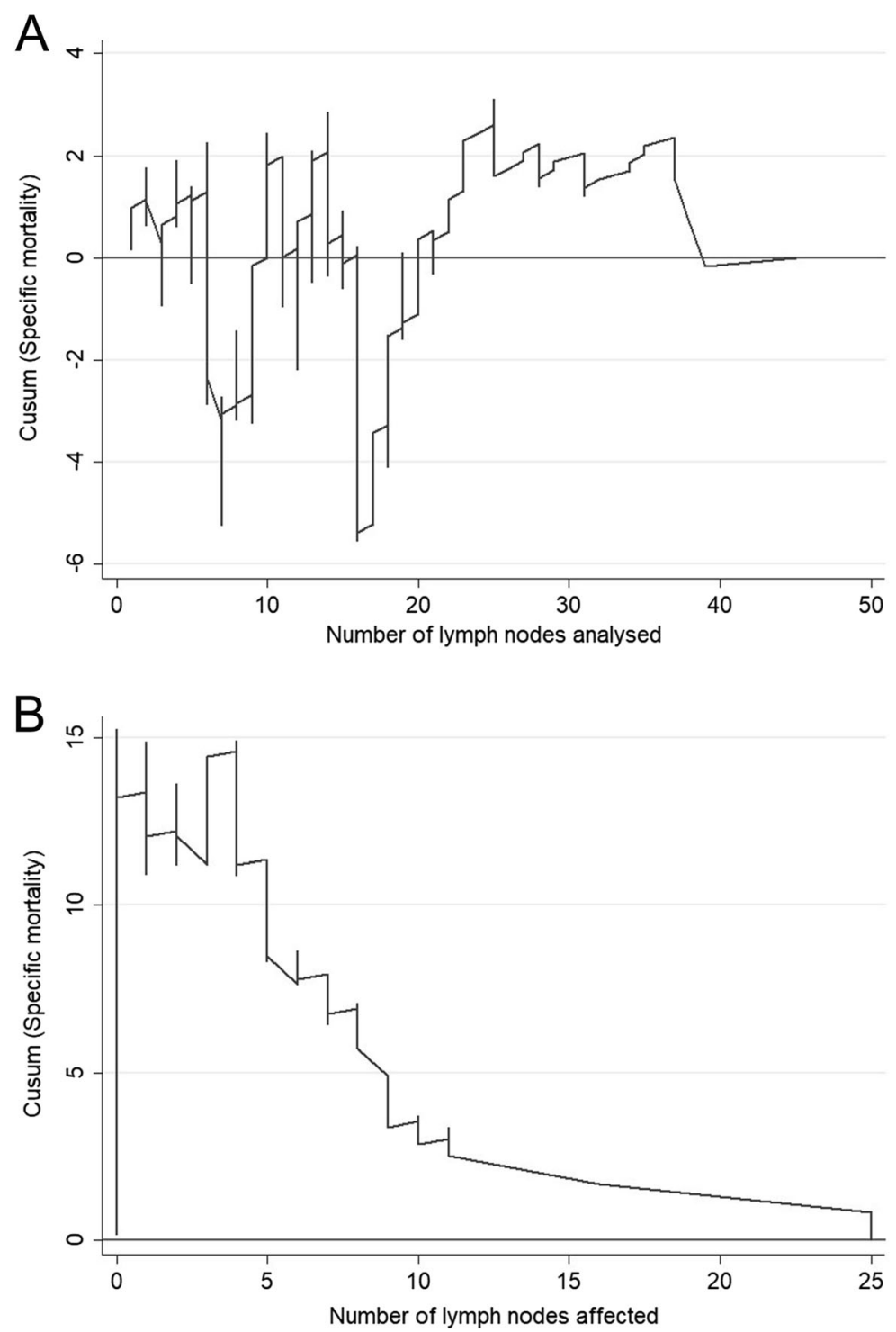

Fig. 2 CUSUM curves. a Specific mortality according to the number of lymph nodes analysed. $\mathbf{b}$ Specific mortality according to the number of lymph nodes affected

CUSUM charts have been used for this type of assessment. CUSUM charts are very useful for detecting subtle changes in the trend of any process [10], and their use is becoming more widespread in medical fields [11], especially in the study of learning curves $[15,16]$. Hence, here, we explored their usefulness in the analysis of lymph node status in colon cancer. CUSUM charts are based on sequentially monitoring cumulative performance over time to display the trends in the relationship between two variables: a qualitative, binary, result variable ( $Y$ axis) and a quantitative variable which can predict this result ( $X$ axis). Thus, the horizontal axis represents the cases over time and, bellow the null line, the vertical axis indicates the lives saved compared to the number of expected saved lives [14].

Following a meeting of experts in Sydney in 1991, the international consensus on the minimum number of lymph nodes that should be analysed to be able to correctly stage colon cancer was set at 12 , and the international community subsequently adopted this number as optimal $[17,18]$. The data that we present here clearly agree that the minimum number of nodes required for an accurate prognostic diagnosis in these patients is 12 (Fig. 1a, b). However, we also show that collecting many more lymph nodes (20 or more) would be advisable because an increased risk of mortality persists when fewer are collected. This may be 

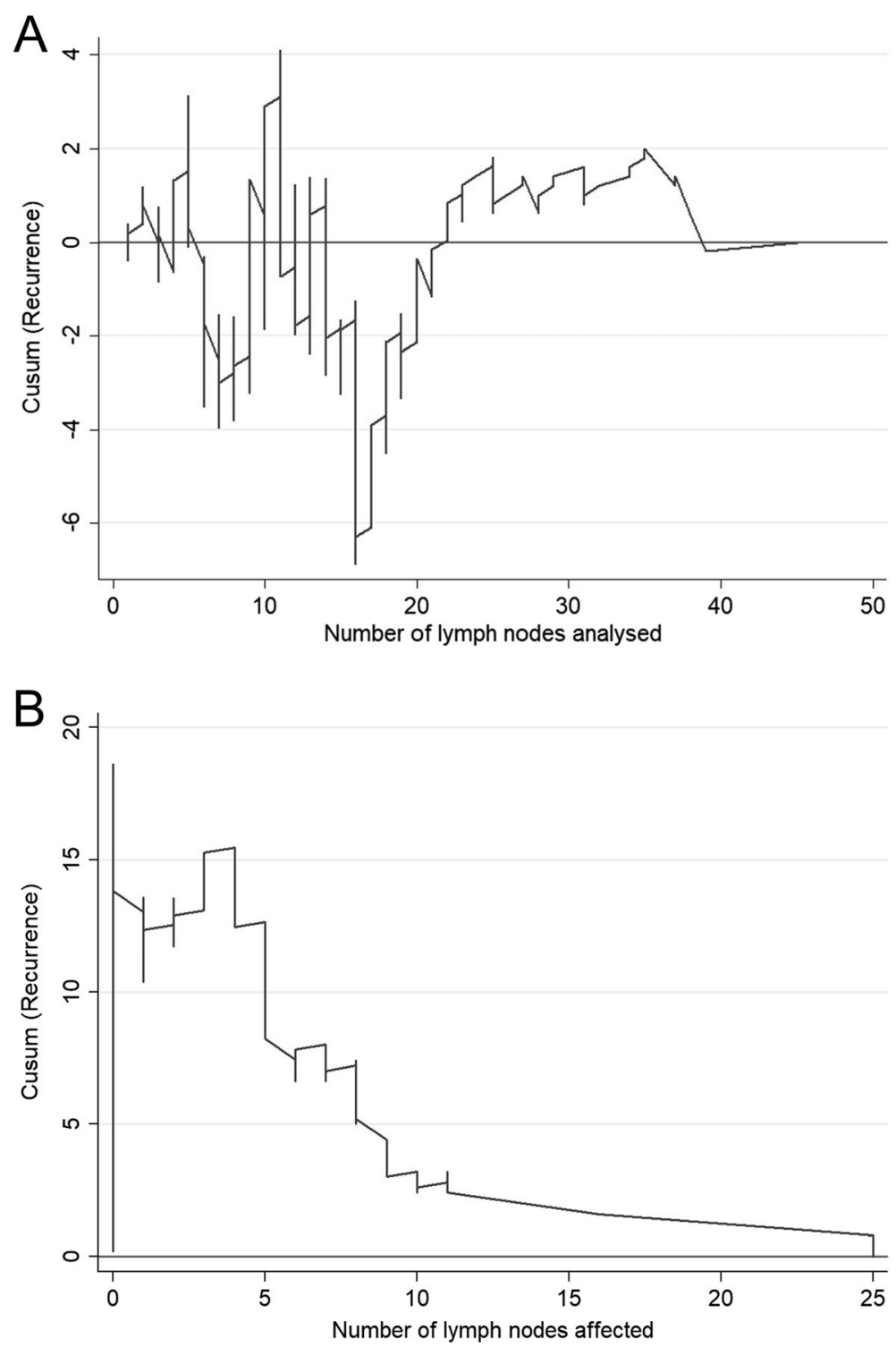

Fig. 3 CUSUM curves. a Recurrence according to the number of lymph nodes analysed. $\mathbf{b}$ Recurrence according to the number of lymph nodes affected

because the disease stage may be underestimated in patients with fewer analysed lymph nodes. Coinciding with our results, many recent studies have questioned the use of this number of lymph nodes [2] and recommend retrieving as many nodes as possible $[3,19]$.

In this sense, identification of a significant cutoff number of 20 lymph nodes in this study is of great importance, both in terms of overall survival (Fig. 1a) and in other variables, including mortality (Fig. 2a) and recurrences (Fig. 3a). Moreover, as more positive lymph nodes are found, overall mortality (Fig. 1b), specific mortality (Fig. 2b), and recurrence (Fig. 3b) also increase; thus, the more lymph nodes affected, the higher the risk. The use of LNR - the ratio between affected and analysed lymph nodes-has been previously reported in several studies which consider it a prognostic factor more important than the specific number of nodes analysed [5, 20]. Furthermore, LNR can also be used in cases where data for the recommended minimum number of lymph nodes are not available-as in more than $50 \%$ of the patients included in the population registry we used in this study. As shown in Fig. 6, the LNR is equivalent to the $\mathrm{pN}$ in cases with high-quality nodal analysis (more than 20 lymph nodes analysed). Therefore, CUSUM charts 


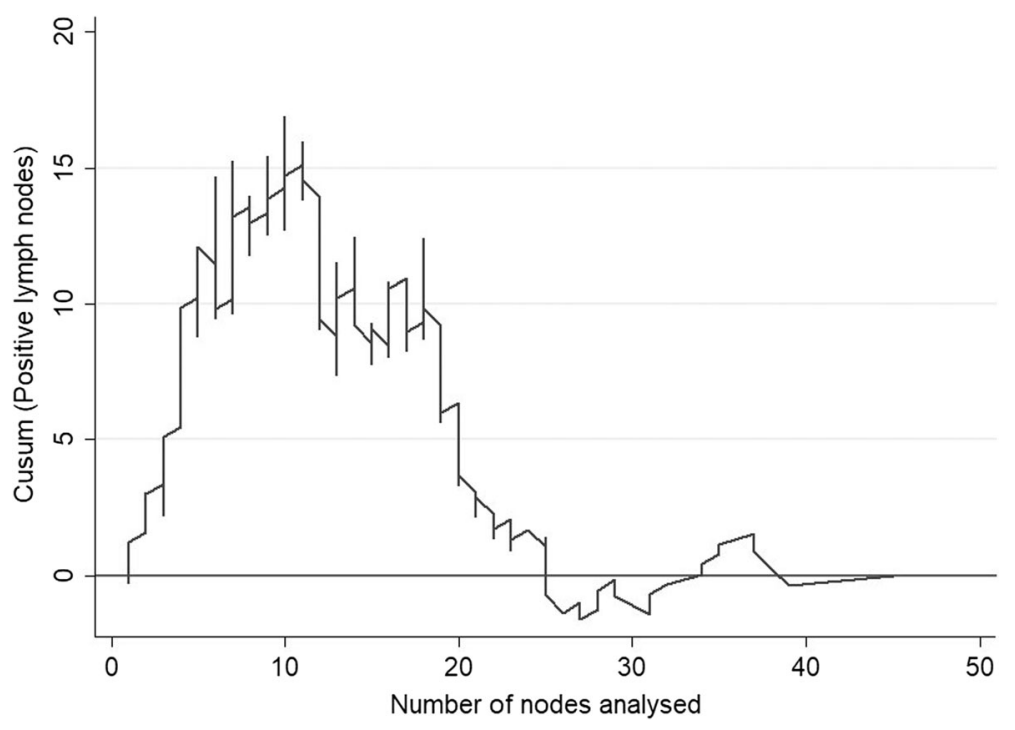

Fig. 4 CUSUM curve. Positive lymph nodes according to the number of nodes analysed

appear to be most useful for choosing the best discriminative cutoff nodal ratio for survival prognosis in different cancer types.

Using the aforementioned statistical methods, CUSUM curves can be used to identify the groups that best discriminate the prognosis on the basis of a given result variable. Categorising highly discriminant prognostic variables in this way will always maximally stratify the main outcome in randomised clinical trials or, for non-randomised trials, will produce the best adjustment of the confounding factors. This is a universal rule of all statistical analyses and helps us to discover the best treatment for various patient groups.
In summary, our analysis with CUSUM control charts reinforces the unquestionable importance of analysing at least 12 lymph nodes in patients with colon cancer in order to accurately estimate their prognosis. However, our results highlight the fact that 12 nodes must be the minimum number and that 20 or more nodes should be analysed to obtain the most useful and highest quality information. Our findings indicate that the analysis of at least 20 lymph nodes is a more appropriate cutoff for accomplishing the demanding objective of the high-quality diagnosis of prognosis in colon cancer patients.

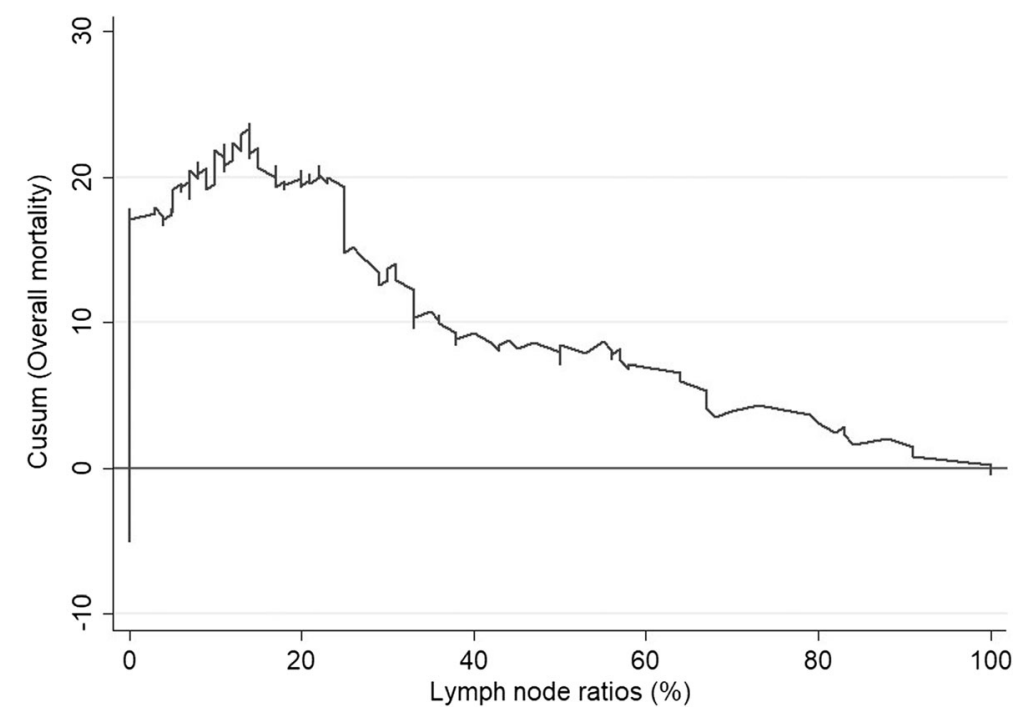

Fig. 5 Overall survival according to the lymph node ratios (LNRs) 


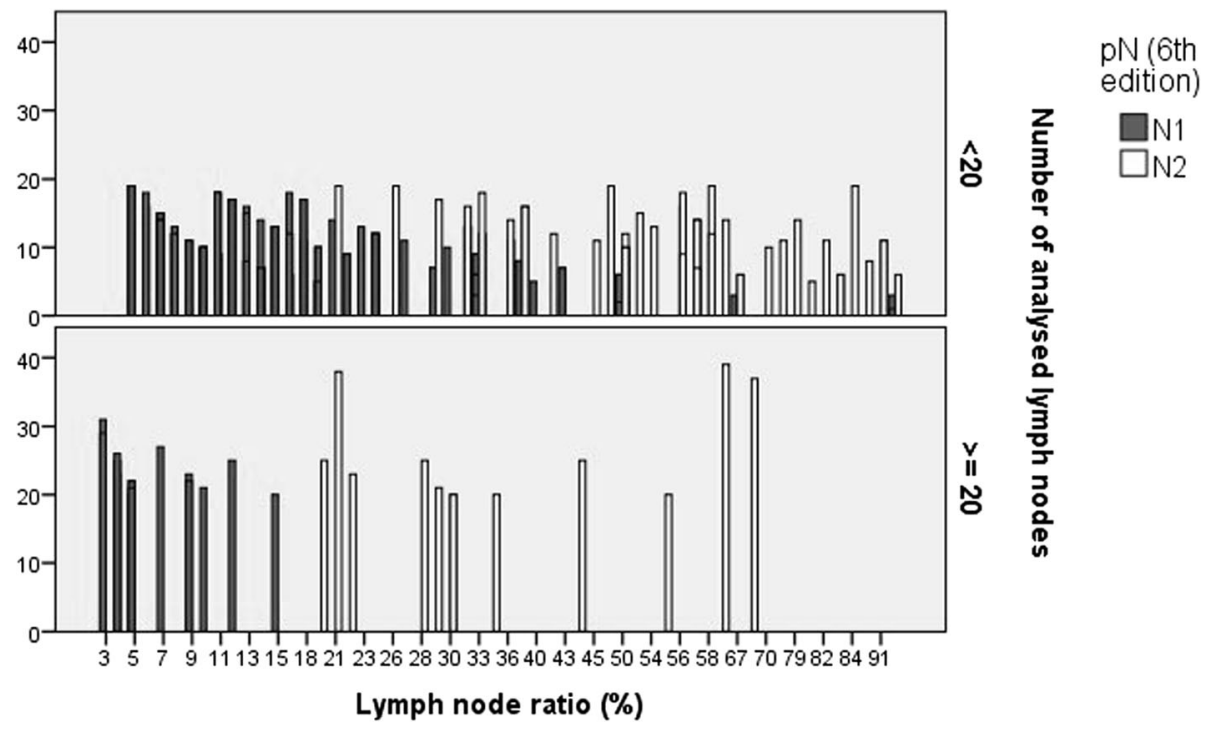

Fig. 6 Lymph node ratios versus pN classifications

\section{Conclusions}

Twelve nodes must be the minimum number analysed in colon cancer to accurately estimate patient prognosis. However, the analysis of at least 20 lymph nodes is a more appropriate cutoff for accomplishing the demanding objective of the high-quality diagnosis of prognosis.

\section{Abbreviations}

CUSUM: Cumulative summation of differences; LNR: Lymph node ratios; UICC: Union for International Cancer Control

\section{Acknowledgements}

None.

\section{Funding}

The paper was funded by Fundación Hospital Provincial de Castellón. No funding was received for this study.

\section{Availability of data and materials}

The primary dataset will not be shared because it is subject to confidentiality restrictions.

\section{Authors' contributions}

CFS and JES planned and designed the study. CFS is the principal investigator and performed the data analysis. JES conducted the statistical analyses. CFS and DMR wrote the manuscript. JES critically reviewed the article. All authors read and approved the final manuscript.

\section{Ethics approval and consent to participate}

The patients' right to data confidentiality and privacy were specifically preserved and bioethical approval for the study was obtained from the cancer registry. Because this was a retrospective study, we did not perform any direct patient interventions. However, the patient confidentiality rules set in place at our centre were always respected and the work was approved by the clinical research and bioethics committee at our centre (PIC: 2013/2/CIR).

\section{Consent for publication}

Not applicable.

\section{Competing interests}

The authors declare that they have no competing interests.

\section{Publisher's Note}

Springer Nature remains neutral with regard to jurisdictional claims in published maps and institutional affiliations.

\section{Author details}

'Department of Surgery, Division of Colorectal Surgery, Consorcio Hospitalario Provincial de Castellón, Av. Doctor Clara, 19, 12002 Castellón, Spain. ${ }^{2}$ Department of Surgery, Hospital General de Castellón, Av. Benicassim s/n, 12004 Castellón, Spain.

Received: 10 May 2018 Accepted: 21 November 2018 Published online: 30 November 2018

\section{References}

1. Generalitat Valenciana. Plan Oncológico de la Comunidad Valenciana 2002-2006. Valencia: Conselleria de Sanitat. Generalitat Valenciana; 2006.

2. Johnson PM, Porter GA, Ricciardi R, Baxter NN. Increasing negative lymph node count is independently associated with improved longterm survival in stage IIIB and IIIC colon cancer. J Clin Oncol. 2006;24: 3570-5.

3. Swanson RS, Compton CC, Stewart AK, Bland KI. The prognosis of T3NO colon cancer is dependent on the number of lymph nodes examined. Ann Surg Oncol. 2003;10:65-71.

4. Shia J, Wang H, Nash GM, Klimstra DS. Lymph node staging in colorectal cancer: revisiting the benchmark of at least 12 lymph nodes in $\mathrm{R} 0$ resection. J Am Coll Surg. 2012;214:348-55

5. Ceelen W, Van Nieuwenhove Y, Pattyn P. Prognostic value of the lymph node ratio in stage III colorectal cancer: a systematic review. Ann Surg Oncol. 2010;17:2847-55.

6. Hernanz F, Revuelta S, Redondo C, et al. Colorectal adenocarcinoma quality of the assessment of lymph node metastases. Dis Colon Rectum. 1994;37: $373-7$.

7. Leibl S, Tsybrovskyy O, Denk H. How many lymph nodes are necessary to stage early and advanced adenocarcinoma of the sigmoid colon and upper rectum? Virchows Arch. 2003;443:133-8.

8. Grunkemeier GL, Wu YX, Furnary AP. Cumulative sum techniques for assessing surgical results. Ann Thorac Surg. 2003;76:663-7.

9. Yap $\mathrm{CH}$, Colson ME, Watters DA. Cumulative sum techniques for surgeons: a brief review. ANZ J Surg. 2007;77:583-6.

10. Royston P. The use of cusums and other techniques in modelling continuous covariates in logistic regression. Stat Med. 1992;11:1115-29. 
11. Woodall WH. The use of control charts in health-care and public-health surveillance. Journal of Quality Control. 2006;38:89-104.

12. Gatta G, Zigon G, Aareleid T, Ardanaz E, Bielska-Lasota M, Galceran J, Góźdź S, Hakulinen T, Martinez-Garcia C, Plesko I, Zakelj MP, Rachtan J, Tagliabue G, Vercelli M, Faivre J. Patterns of care for European colorectal cancer patients diagnosed 1996-1998: a EUROCARE high resolution study. Acta Oncol. 2010; 49:776-83.

13. Barrio I, Arostegui I, Rodríguez-Álvarez MX, Quintana JM. A new approach to categorising continuous variables in prediction models: proposal and validation. Stat Methods Med Res. 2017;26:2586-602. https://doi.org/10. 1177/0962280215601873

14. Noyez L. Control charts, Cusum techniques and funnel plots. A review of methods for monitoring performance in healthcare. Interact Cardiovasc Thorac Surg. 2009;9:494-9.

15. Miskovic D, Ni M, Wyles SM, Tekkis P. Hanna GB. Learning curve and case selection in laparoscopic colorectal surgery: systematic review and international multicenter analysis of 4852 cases. Dis Colon Rectum. 2012;55: 1300-10.

16. Buchs NC, Pugin F, Bucher P, Hagen ME, Chassot G, Koutny-Fong P, Morel P. Learning curve for robot-assisted roux-en-Y gastric bypass. Surg Endosc. 2012;26:1116-21.

17. Fielding LP, Arsenault PA, Chapuis PH, Dent O, Gathright B, Hardcastle JD, Hermanek P, Jass JR, Newland RC. Clinicopathological staging for colorectal cancer: an international documentation system (IDS) and an international comprehensive anatomical terminology (ICAT). J Gastroenterol Hepatol. 1991;6:325-44.

18. Nelson H, Petrelli N, Carlin A, Couture J, Fleshman J, Guillem J, Miedema B, Ota D, Sargent D; National Cancer Institute Expert Panel. Guidelines 2000 for colon and rectal cancer surgery. J Natl Cancer Inst 2001;93:583-596.

19. Jestin P, Påhlman L, Glimelius B, Gunnarsson U. Cancer staging and survival in colon cancer is dependent on the quality of the pathologists' specimen examination. Eur J Cancer. 2005;41:2071-8.

20. Gönen M, Schrag D, Weiser MR. Nodal staging score: a tool to assess adequate staging of node-negative colon cancer. J Clin Oncol. 2009;27: 6166-671.

Ready to submit your research? Choose BMC and benefit from:

- fast, convenient online submission

- thorough peer review by experienced researchers in your field

- rapid publication on acceptance

- support for research data, including large and complex data types

- gold Open Access which fosters wider collaboration and increased citations

- maximum visibility for your research: over $100 \mathrm{M}$ website views per year

At $\mathrm{BMC}$, research is always in progress.

Learn more biomedcentral.com/submissions 